Original Research Paper

\title{
Architecture of Low Power Energy Harvester Using Hybrid Input of Solar and Thermal for Laptop or Notebook: A Review
}

\author{
${ }^{1,3}$ Hanani Mohamed Nadzirin, ${ }^{1}$ Jahariah Sampe, ${ }^{1}$ Muhammad Shabiul Islam and ${ }^{2}$ Noorfazila Kamal \\ ${ }^{1}$ Institute of Microengineering and Nanoelectronics (IMEN), \\ ${ }^{2}$ Department of Electrical, Electronic and System Engineering, \\ Faculty of Engineering and Built Environment, \\ Universiti Kebangsaan Malaysia (UKM), 43600 Bangi, Selangor, Malaysia \\ ${ }^{3}$ Electrical \& Electronics Section, Universiti Kuala Lumpur, \\ Malaysia France Institute, Jalan Teras Jernang, 43650 Bandar Baru Bangi, Selangor, Malaysia
}

Article history

Received: 13-06-2016

Revised: 9-09-2016

Accepted: 10-09-2016

Corresponding Author:

Hanani Mohamed Nadzirin

Jahariah Sampe

Institute of Microengineering and Nanoelectronics (IMEN), Universiti Kebangsaan Malaysia (UKM), 43600 Bangi Selangor, Malaysia

Email: hananinadzirin@yahoo.com jahariah@ukm.edu.my

\begin{abstract}
This paper aims to develop and design the architecture of Low Power Hybrid Energy Harvester (LPHEH) using the hybrid input of solar and thermal that can be harvested for self-powered laptop or notebook. This research will focus on the development of the high performance boost power converter to power up any laptop or notebook and design power management system of the hybrid input of solar and waste heat that has been released. The main function of the boost converter is to generate a sufficient DC power supply for laptop or notebook. The second stage focuses on investigation, design and development of the architecture to convert the solar and waste heat energy to reusable energy. The solar energy harvesting elements such as solar panels and energy storage components are used and to be matched to each other with sufficient energy required to increase the energy harvesting efficiency. The proposed design performances will be described using PSPICE software simulation and experimental results. The final stage is to integrate the first stage and second stage, power management module and charge controller module. Then, the developed LPHEH will be simulated, synthesis using Mentor Graphics and coding using Verilog and then download the LPHEH modules into FPGA board for real time verification. The layout architecture of LPHEH will be tested and analyzed using CALIBRE tools from Mentor Graphics. The expected result from this LPHEH is to get $12 \mathrm{~V}$ to $20 \mathrm{~V}$ of the regulated output voltage from minimum input voltage sources range from $5 \mathrm{~V}$ to $12 \mathrm{~V}$ with efficiency more than $90 \%$.
\end{abstract}

Keywords: Low Power Hybrid Energy Harvester (LPHEH), Self-Powered, Power Management, Solar and Thermal

\section{Introduction}

Low power, portable communication and computer devices could be one of the highest market need and demand for energy harvesting (Yogesh and Chandrakasan, 2011). With the demand for electronic devices such as laptop and notebook, consumers now require more functionality with better performance, light weight, smaller size and independent from an external source (Abdelmoaty and Fayed, 2015). However, there are challenges and limitations in improving battery lifespan (Carreon-Baustista et al., 2014). Abdelmoaty and Fayed (2015) mentioned that first attempts to promote battery span and minimize the power usage of the electronic devices by decreasing the power absorbed in analog and digital circuits. Second, they also mentioned that the industry is now considering another way to improve the battery life span in portable electronic devices by harvesting energy from the environment. This application is to promote the battery life span in powering the electronic devices and to make it possible to recharge by itself. All laptops are assigned a power rating to let users know how long the battery can last in between charges. The input voltage refers to how much energy the laptop's battery 
consumes. This number should be matched with output voltage number, which is how much energy is transferred through the adapter. Industry standards have been popularizing $12 \mathrm{~V}$ and $19 \mathrm{~V}$ for many laptop models. The output voltage of the adapter is directly related to the input voltage requirement for the laptop. Some laptop companies have been using $12 \mathrm{~V}$ and $19 \mathrm{~V}$ input voltage for most of the models. However, there is a wide range between $9.8 \mathrm{~V}$ and $24 \mathrm{~V}$ available on the market. Most laptops today require no more than a total of the $70 \mathrm{~W}$ power adapter that supplies input power. It should be noted there are specialty laptops that require a $90 \mathrm{~W}$ power, particularly those that handle high-end graphics cards or have powerful multitasking capabilities. These laptops are designed for gaming and working with digital media. Every electricity consuming device wastes energy and the heat from laptop or notebook is a wasted energy. When it comes to electronics, better energy efficiency through harvesting technologies using the hybrid input of solar and Thermoelectric Generator (TEG) from wasted heat can also reduce the need for batteries.

Ambient energy harvesting is the process of generating energy from external sources such as solar and thermal and stored for electronic devices such as laptop or notebook. Piezoelectricity, solar power, thermoelectricity, ocean waves and physical motions are the examples of a few techniques used in energy harvesting (Sarker et al., 2013). Abdelmoaty and Fayed (2015) stated that Photovoltaic (PV) cells contribute more energy compared to other ambient sources such as Radio Frequency (RF), vibrational and thermal. Hence, PV cells are better and reliable sources for electronic devices and applications especially laptop and notebook. Yildiz et al. (2014) stated that TEGs are devices that transform the temperature gradient into electricity and TEGs are produced from Thermoelectric Modules (TEM) which consist of the solid-state integrated network that employed the Seebeck, Thomson and Peltier thermoelectric effects (Abdul Rahman et al., 2013). TEGs require heat as an energy source and it can produce power as long as there is a heat source (Han et al., 2010). In this research, TEG or Seebeck generator is used to convert the temperature differences between the ambient source and waste heat energy of laptop or notebook directly into electrical energy (Calhoun et al., 2010). For solar energy, PV will be used to convert light (photons) to electricity (voltage), which is called the PV effect. Then, the hybrid sources of solar and TEG harvesting will be combined to develop hybrid LPHEH for laptop or notebook. The goal of this research is to integrate several vital functions into a single component to improve and to be implemented to the overall performance of the system.

\section{Related Research}

Many potential ambient power sources for energy harvesting were investigated in most of the existing research (Alhawari et al., 2013). Energy harvesting hybrid sources are categorized as power distribution or power scavenging methods that allow laptop or notebook to be totally battery independent and self-sustaining. This literature review shows that the selection of hybrid energy sources of thermal and solar need to be considered according to the application characteristics. The proposed design performances will be described using simulation and experimental results. In this research, the ambient energy sources of hybrid thermal and solar input will be presented and the resources according to their characteristics will be summarized. Hybrid energy scavenging or power harvesting from waste heat thermal and solar power are the approach that can be practiced to develop the architecture of LPHEH.

Power harvested from only one source is not sufficient for laptop and notebook since the ambient source is depending on the environment and the efficiency of the energy conversion (Hamilton, 2012). Hybrid sources are proposed to overcome the limitation of a single source, where the harvesting system is controlled by a few types of ambient sources (Torres et al., 2008). The secondary energy sources such as solar and thermal will be used when the main source is not enough to supply the power for the load. The configuration of thermal and solar energy together with the rechargeable battery is mostly used as the hybrid energy sources since the rechargeable battery can buffer the harvested environmental energy when the environmental power is high. It can provide instantaneous high power to the load when the ambient energy is not enough. Solar energy is an energy which is limitless and the cleanest renewable energy from the sun that is converted into electrical energy. The sun radiates electromagnetic energy in the form of the stream of photons to earth. For solar energy, photovoltaic (PV) cell is used to transform the incident solar energy to electrical energy. The PV cell is built from a reverse biased p-n junction. As the n-type side of the $p-n$ junction is exposed to the sunlight, photons will be trapped within the depletion region and generate the electron-hole pairs.

Yen and Sanjib (2011) had presented a study on energy harvesting from the surrounding thermal heat and light to deal with the constrain of having only one source. They developed single power management module to extend the lifespan of the wireless sensor node with minimum power losses and less expensive. The power consumption is around $135 \mu \mathrm{W}$ and they performed an efficiency of $90 \%$ for power management. Kadivel et al. (2012) presented a single power management unit at $330 \mathrm{mV}$ start-up voltage and the charger efficiency of more than $80 \%$. Saurav and Anantha (2012) studied in a dual path system consists of multi-input and output with the maximum efficiency improved to $11 \%$ to $13 \%$. They discovered that the system can produce $20 \mathrm{mV}$ to $5 \mathrm{~V}$ input voltages and 
manage to achieve greater output power by utilizing only a single inductor. Beker et al. (2011) studied the integration of Electromagnetic (EM) energy harvesting to piezoelectric (PZT) based energy harvester for computer keyboard application. They analyzed two types of designs using a prototype model to generate greater output power. From the simulations, the maximum output power of $1.20 \mathrm{nW}$ can be achieved by using a fixed coil implementation while $2.81 \mu \mathrm{W}$ power can be generated by integrating a frequency up-conversion based structure with the PZT beam. From the integration of electromagnetic energy conversion, they discovered that the total output power of $19.76 \mu \mathrm{W}$ can be produced under active typing scenarios with the proposed hybrid system. They predicted that further design optimizations and improvements may increase the output power. Three input sources which consist of motion, thermal and indoor light were combined and have been studied by Michelle et al. (2014). They discovered that the input voltage from $18 \mathrm{mV}$ to $907 \mathrm{mV}$ can be harvested to produce the output voltage of $310 \mathrm{mV}$ to $27.9 \mathrm{~V}$. For boost converter, these three inputs impedances are matched to its load to get the maximum harvested power.

One of the recent study and research is a selfpowered laptop or notebook using single source waste heat energy harvesting done by Mohd Izam and Jahariah (2013). In this study, a research was done to test and analyze four different types of Thermoelectric Module (TEM) from different manufacturers (Germany and USA) using different parameters values. A TEM is a circuit network consists of thermoelectric materials that produce electricity directly from heat. It consists of two dissimilar thermoelectric materials of n-type (negatively charged) and p-type (positively charged) semiconductors joined at their ends. Few experiments have been performed to verify the linear relationship among voltages, current, power and temperature gradient with respect to time. The device is then attached together with power management circuit and charge controller circuit to determine the feasibility of battery recharging. The verification results show that the maximum power outputs are $5 \mathrm{~W}$ and $8 \mathrm{~W}$ during charging without and with load respectively. However, the notebook cannot be switched on directly from the TEMs because of the low output voltage of the TEM. The power management module then used to amplify the output voltage to ensure the battery is keep charging smoothly using charge controller circuit (Inge et al., 2009). Then, a high performance DC-DC Power Converter (Boost Converter) is designed. This designed boost converter is capable of increasing the output voltage and producing maximum power as required by the notebook or laptop (Motiur et al., 2015). The testing and verification results show that the notebook can power up and operate double and triple of hours as compared to a normal operating notebook.

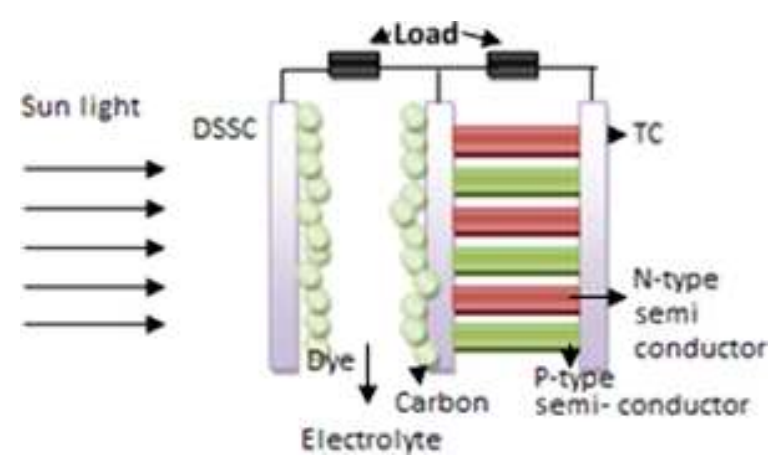

Fig. 1. The hybrid cell for harvesting light and thermal energy (Xu et al., 2012)

Mohd Izam and Jahariah (2013) discovered that the harvested output voltage increased when the temperature difference increased with multiple thermoelements joined together to form a TEM. However, the thermal losses between the hot and cold side of the module caused the current to decrease. The cooling system was then used to release and maintain the temperature different. This research was done to determine the type of TEMs and cooling system that manage to generate greater, stable and more efficient power energy. They discovered that cooling system with water based was better, more stable and more capable of controlling the temperature difference between the hot and cool side of the TEM.

A recent study by $\mathrm{Xu}$ et al. (2012) shows that heat is a result of energy conversion process in photovoltaic devices, but lost to the surroundings. Thus, $\mathrm{Xu}$ et al. (2012) presented a hybrid cell to combine the harvested input of the solar energy and the generated heat in order to increase the efficiency of solar energy conversions shown in Fig. 1. It consisted of a dual compartment of Thermoelectric Cell (TC) and a dye-sensitized solar cell (DSSC). Solar energy is first transformed to electricity in the DSSC and the heat is then transmitted to the TC. The DSSC will also produce heat which is transferred to the TC consisting of semiconductor $p-n$ junction. The temperature difference between the two sides of the TC changes the diffusion carrier density of the thermoelectric material that produces the thermoelectric voltage. The overall output voltage of the Hybrid Cell (HC) is obtained by total voltages produced by DSSC and the TC. With the proposed architecture, $\mathrm{Xu}$ et al. (2012) measured an open-circuit voltage in 732-911 mV range. Kalyanaraman and Babu (2010) had presented the design and architecture of energy conservation system for mobile phones and laptop keyboards. They developed a model of the piezoelectric transducer for electronic gadgets such as mobile phone, the prototype of the power harvesting circuit, and the overall circuit to charge the mobile battery applying the generated harvesting energy. The material used for the application is a piezoelectric PZT with $1.5 \mathrm{Mpa}$ lateral stress 
operating at $15 \mathrm{~Hz}$. The mechanism comprises of elongated (PZT) to generate electric power from mechanical energy. The energy/power density is $6 \mathrm{~mW} / \mathrm{cm}^{3}$ and the volume of the material used is $0.2 \mathrm{~cm}^{3}$. The output power generated is $1.2 \mathrm{~W}$ and the output voltage is $9 \mathrm{~V}$. This voltage can be applied to attain the desired amount of charge after being processed. Porcarelli et al. (2012) had developed a multi harvester architecture with hybrid storage devices for low power systems and configurable capabilities. This design integrates high efficiency of energy harvesting and micro fuel cell technology. The solar energy harvesting technology consists of a model of the solar cell and a boost converter to produce an efficiency of $86 \%$.

Abdelmoaty and Fayed (2015) proposed a platform, which is designed to manage a PV energy with greater voltage than the required load voltage with power as high as $10 \mathrm{~W}$. Thus, it meets the requirement for electronic applications such as tablets and laptops. The proposed research has been implemented in $0.25 \mu \mathrm{m}$ standard CMOS technology using Verilog coding with a short circuit current of a PV cell equals to $400 \mathrm{~mA}$ and an open-circuit voltage of $7 \mathrm{~V}$. The maximum power point of $2 \mathrm{~W}$ and the load voltage is regulated to $1.8 \mathrm{~V}$ with $600 \mathrm{~mA}$ load current. Table 1 below shows the summary of the hybrid energy harvester circuit performance from past researches on low power energy harvester. Semsudin et al. (2015a) had presented the architecture of a boost converter micro energy harvesting system using thermal and vibration from a human body for biomedical devices. The inputs of $0.2 \mathrm{~V}, 0.3 \mathrm{~V}$ and $0.5 \mathrm{~V}$ are obtained from thermal, vibration and combination of both (hybrid) sources respectively. All these inputs are step-up by the boost converter to obtain the output voltage of $2.0 \mathrm{~V}$ to 4.0V.They discovered that the optimum inductor value for these input sources is set to $0.9 \mu \mathrm{H}$ which produces the desired output of $2.0 \mathrm{~V}$ to $4.0 \mathrm{~V}$. Farah Fatin et al. (2015a) had presented a study on ultra-low voltage rectifier circuit for RF-based energy harvester to analyze the performance of the proposed full wave rectifier circuit. A voltage boosting network with passive components has been reviewed to find the optimum value of the inductor and capacitor that can minimize the problem of the low input voltage in energy harvester. The output voltage produced approximately $400 \mathrm{mV}$ greater than the existing full wave rectifier with similar input which shows that the input range can be increased before converting to dc output.

Every laptop or notebook battery carries a certain reservoir or capacity of charge per cycle. The battery lasts longer depending on the power management system and how the user using the laptop or notebook. The batteries energy will drop because of the highest energy consuming functions and how frequently it is used daily. The existing notebook powering system normally required a battery and the battery need to recharge again by plugging to the AC power source. Laptop or notebook need to be portable and handheld.

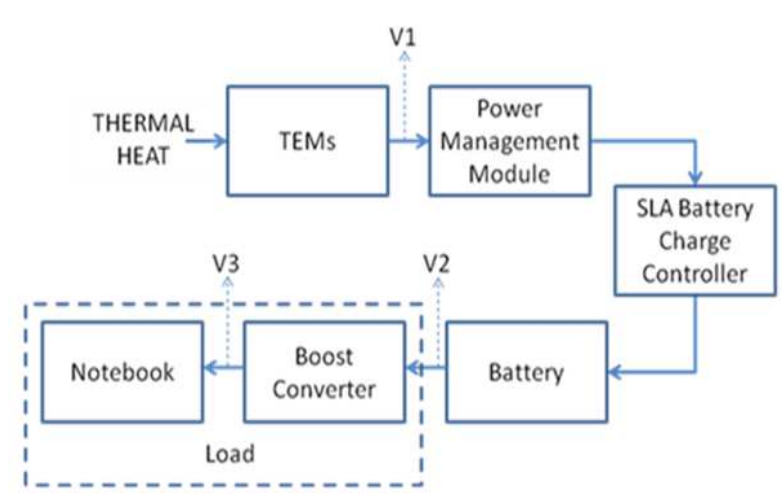

Fig. 2. Block diagram of the Complete Proposed System (Mohd Izam and Jahariah, 2013)

Thus, these systems have the limitation on its application as they depending only on the external power source for charging and also to power up the system (Basel et al., 2009). The energy resources also become extinct therefore the reusable energy from the alternative source such as heat or thermal energy (Han et al., 2010) and solar energy is a must. Energy harvesting is likely to replace many of the conventional batteries sold every year that will involve long life rechargeable batteries and super-capacitors for storage of the harvested energy (Doms et al., 2009). The self-powered notebook using a single source from recovered waste heat energy have been introduced and developed in order to improve the power consumption and long lasting powered system of the notebook as shown in Fig. 2 by Mohd Izam and Jahariah (2013).

\section{Problem Statement}

The aim of this research is to overcome the problem faced by past researchers to support conventional storage technologies, which are not fully efficient at powering electronic applications by building energy harvesting system to generate and produce electrical energy from thermal and solar energy sources. In recent years, there are few new harvesting technologies applications and systems have been introduced to improve life in general. Many of these applications utilize new harvesting technologies. This research will highlight the problem with several examples of unused waste energy resources that could be harvested by supporting several of these conventional energy producing devices. The performance of low power energy harvesting system should be tested to extract maximum efficiency to assist conventional power sources for electronic devices and get electronic systems to run on thermal and solar energy sources (Dayal et al., 2013). A secondary problem is to examine reliability, responsiveness, scalability, and power efficiency of the thermal and solar energy sources in order to design an efficient energy harvesting system according to the maximum needs of the application. 


\begin{tabular}{|c|c|c|c|c|c|c|c|c|c|c|c|c|}
\hline $\begin{array}{l}\text { Researcher } \\
\text { (year) }\end{array}$ & Sources & Architecture & $\begin{array}{l}\mathrm{V}_{\mathrm{IN}} \\
(\mathrm{V}) \\
\end{array}$ & $\begin{array}{l}V_{\text {OUT }} \\
(\mathrm{V})\end{array}$ & $\begin{array}{l}\mathrm{P}_{\mathrm{IN}} \\
(\mu \mathrm{W})\end{array}$ & $\begin{array}{l}P_{\text {OUT }} \\
(\mu \mathrm{W})\end{array}$ & $\begin{array}{l}\text { Boost } \\
\text { converter }\end{array}$ & MPPT & $\begin{array}{l}\text { Start } \\
\text { up }\end{array}$ & $\begin{array}{l}\text { Peak } \\
\mathrm{y}(\%) \\
\end{array}$ & $\begin{array}{l}\text { Process } \\
\text { Tech. }\end{array}$ & Application \\
\hline $\begin{array}{l}\text { Kalyanaraman and } \\
\text { Babu (2010) }\end{array}$ & PZT & $\begin{array}{l}\text { Power Harvesting } \\
\text { System, Mobile Phones, } \\
\text { Laptops }\end{array}$ & Not stated & 9.0 & Not stated & 1.2 & Yes & No & No & Not stated & prototype & $\begin{array}{l}\text { Laptop } \\
\text { /mobile } \\
\text { phone }\end{array}$ \\
\hline $\begin{array}{l}\text { Motiur et al. } \\
\text { (2015) }\end{array}$ & PZT & $\begin{array}{l}\text { Power conditioning } \\
\text { circuit, MPPT algorithm }\end{array}$ & 0.5 & 3.0 & 26667 & 24000 & $\begin{array}{l}\text { Yes } \\
\text { (Charge } \\
\text { pump) }\end{array}$ & Yes & No & 90 & $0.13 \mu \mathrm{m}$ & $\begin{array}{l}\text { Wireless } \\
\text { Sensor } \\
\text { Network }\end{array}$ \\
\hline $\begin{array}{l}\text { Mohd Izam and } \\
\text { Jahariah (2013) }\end{array}$ & TEG & $\begin{array}{l}\text { Boost converter, } \\
\text { charge controller }\end{array}$ & $5-12$ & $12-20$ & $8 \times 10^{6}$ & $14.5 \times 10^{6}$ & Yes & No & No & 93 & Prototype & $\begin{array}{l}\text { Laptop } \\
\text { / Notebook }\end{array}$ \\
\hline $\begin{array}{l}\text { Beker } \text { et al. } \\
\text { (2011) }\end{array}$ & PZT, EM & $\begin{array}{l}\text { Hybrid energy } \\
\text { transduction } \\
\text { harvesting } \\
\text { from keyboard }\end{array}$ & Not stated & Not stated & Not stated & 19.76 & No & No & No & Not stated & Prototype & $\begin{array}{l}\text { Laptop / } \\
\text { Notebook }\end{array}$ \\
\hline $\begin{array}{l}\text { Abdelmoaty and } \\
\text { Fayed (2015) }\end{array}$ & PV & $\begin{array}{l}\text { Single-inductor } \\
\text { based power } \\
\text { supply, regulated } \\
\text { battery charger }\end{array}$ & Not stated & 1.8 & Not stated & $2 \times 10^{6}$ & No & Yes & No & Not stated & Prototype & $\begin{array}{l}\text { Mobile } \\
\text { application/cell } \\
\text { phone/Laptop/ } \\
\text { Notebook/Tablet }\end{array}$ \\
\hline $\begin{array}{l}\text { Farah Fatin Z. et al. } \\
(2015 b)\end{array}$ & $\mathrm{RF}$ & $\begin{array}{l}\text { Rectifier, Control } \\
\text { loop, adaptive control } \\
\text { circuit, regulator } \\
\text { and voltage limiter }\end{array}$ & Not stated & 10 & 2.45 & 6 & Yes & No & No & 60 & 130 & $\begin{array}{l}\text { Micro Power } \\
\text { Healthcare } \\
\text { monitoring } \\
\text { system }\end{array}$ \\
\hline Musa et al. (2016) & PV, TEG & $\begin{array}{l}\text { Low power, } \\
\text { hybrid input, } \\
\text { solar and thermal }\end{array}$ & $5-12$ & $12-20$ & $8 \times 10^{6}$ & $14.5 \times 10^{6}$ & Yes & Yes & Yes & 90 & 130 & $\begin{array}{l}\text { Laptop / } \\
\text { Notebook }\end{array}$ \\
\hline
\end{tabular}

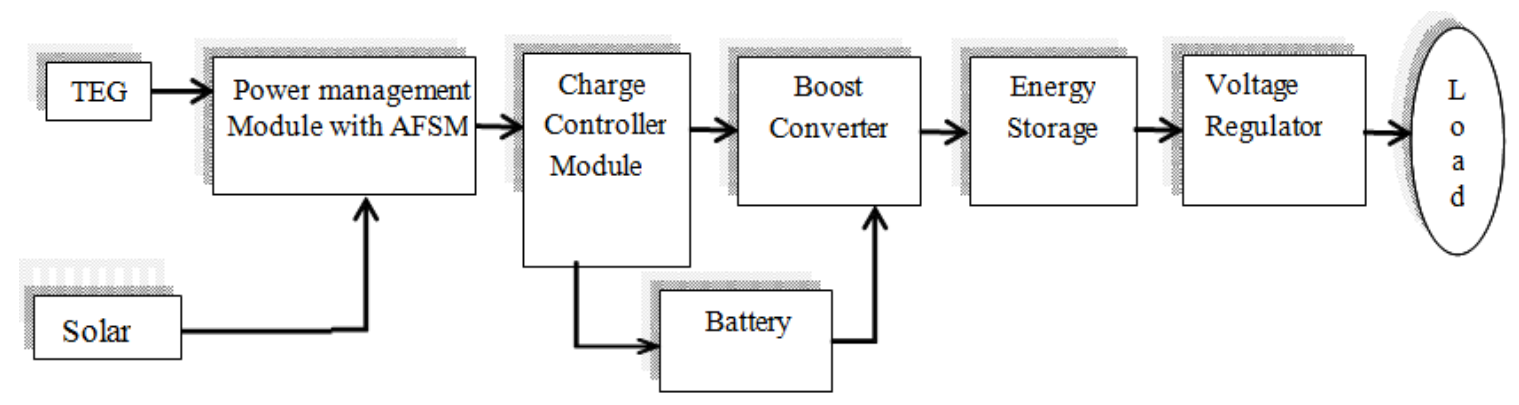

Fig. 3. Proposed Block of LPHEH

For some applications that require extremely small volume and are deployed in the environment that has poor power conditions, the DC-DC converter and battery are usually avoided due to their large size, and the charge pump cannot be used due to its poor power transfer efficiency (Carlson et al., 2009). In order to cater for the unstable and limited capacity characteristics of the energy source and to guarantee the load to operate robustly, a charge based computation methodology is proposed for the architecture of LPHEH. The proposed DC-DC converter or Boost Converter will be designed to be simple, lightweight and small in size as compared to another converter available in the market (Dhople et al., 2010; Weng et al., 2013). Furthermore, this Boost Converter will be designed and implemented using analog circuits. However, this will require more components compared to a Microcontroller-based converter. Comparing the characteristics of different energy harvesting mechanisms, solar energy has the advantages of being available everywhere and having very high power density, and the technology for the photovoltaic cell is mature. In this research, it is important to highlight the problem mentioned by previous researchers in finding the proper input voltage from energy harvesters. Colomer-Farrarons et al. (2011) highlighted that summing the hybrid sources together (solar and TEG) or individually will contribute to the cost increased and power losses. Besides, the parasitic resistance and capacitance will cause conduction and switching losses respectively. Furthermore, leakage current and power used in the control circuit will also contribute in deteriorate the efficiency of the hybrid energy harvester sources. Therefore, two hybrid input sources of TEG and solar will be used in our proposed design to generate a proper input voltage and to be implemented in portable electronic devices such as laptop and notebook (Chandrakasan et al., 2008). The sources can be combined or used separately (Semsudin et al., 2015b).

\section{Description (Proposed Block)}

Refer to Fig. 3, the proposed block diagram for LPHEH system consist of nine blocks which are hybrid input sources of Thermoelectric Module (TEG) and Solar, Power Management Module, Charge Controller Module, Boost Converter, Battery, Energy Storage and Voltage Regulator respectively and finally the load. All of the blocks will be integrated, and to be applied to laptop or notebook as a load. The design architecture will have TEG and solar hybrid inputs to produce the proper threshold input voltage to be implemented in laptop or notebook. 


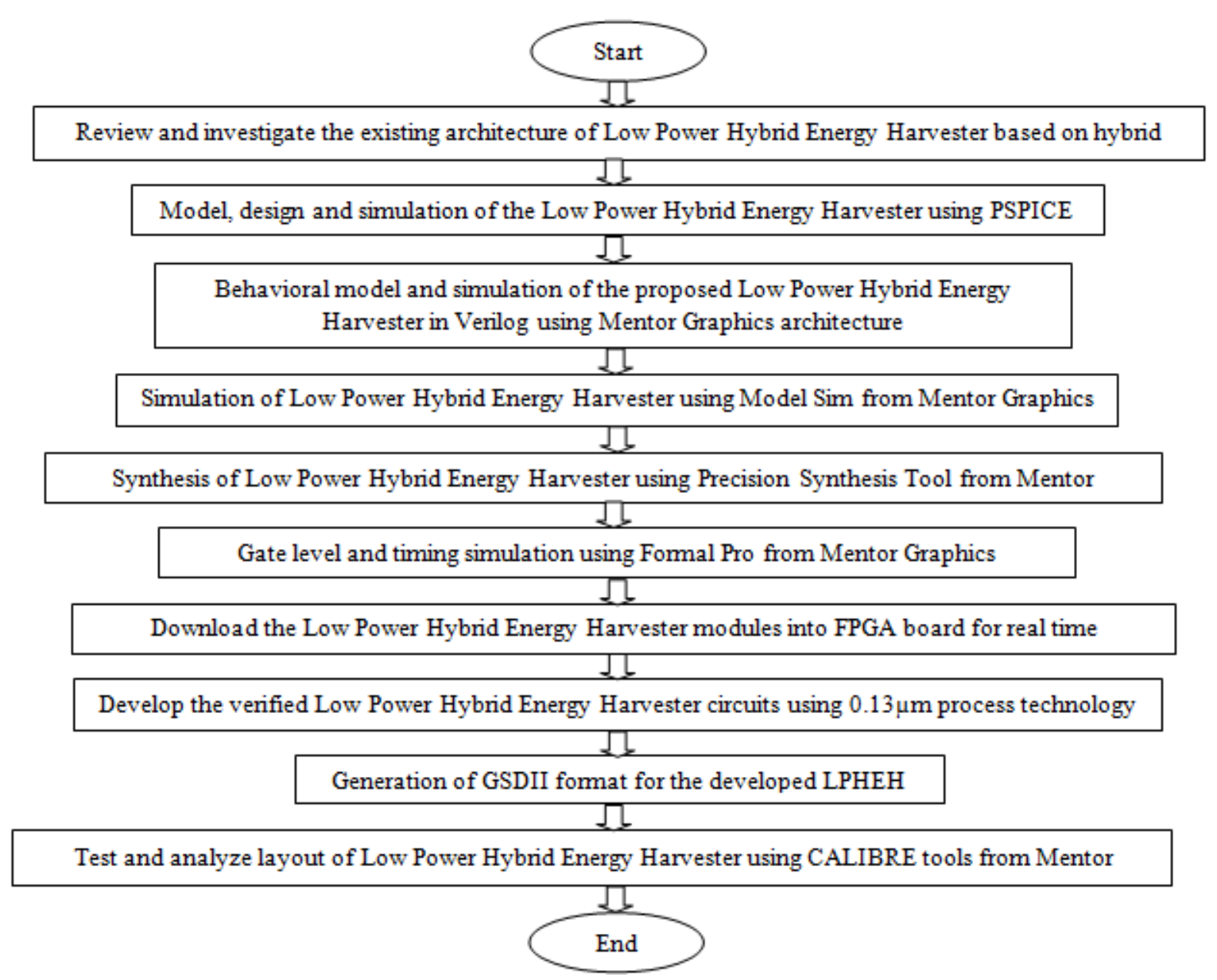

Fig. 4. Flow Chart of Research Activities

Both hybrid input sources from TEG and solar will be connected to a Power Management Module with an Asynchronous Finite State Machine (AFSM) to combine the hybrid input and conduct single or total of the power supplies (Michelle et al., 2014; Shi et al., 2011). The power management module is used to boost and give the maximum energy for charging the battery while the AFSM is used to arrange the TEG and solar hybrid sources when they operating simultaneously. After determining the selected input from Power Management Module with AFSM, the Charge Controller Module (CCM) is used to avoid the TEG or solar modules overcharging the battery which can weaken the battery performance and lifespan (Carlson et al., 2010). The CCM circuit helps the thermal energy source to charge the battery by monitoring and control both the output voltage and current of the input charger. The proposed Boost Converter will be designed with the current and voltage rating requirement for the laptop or notebook must be determined with the input and output voltage is $5 \mathrm{~V}$ and $20 \mathrm{~V}$ respectively. A start-up circuit will be implemented in determining the proper input voltages (Stark et al., 2010). Boost converter or known as DC-DC converter will be applied to generate the input voltage to the desired value and it is commonly used in regulated switch mode power supplies (Musa et al., 2016). The input of these converters is obtained by DC battery and will decrease due to changes of capacity load. The average DC output voltage for the boost converter must be controlled to be equated to the desired value although the input voltage is changing. The development of the boost converter will be designed to achieve the minimum input voltage between $5 \mathrm{~V}$ to $12 \mathrm{~V}$ to a stable output voltage between $12 \mathrm{~V}$ to $20 \mathrm{~V}$ to switch on the notebook. The selfpowered notebook or laptop using recovered waste heat and solar will be a complete system by integrating all the design Electronic Circuits (Power management and Battery Charger Controller) and modules (Thermal Heat and Boost Converter). This thermal source can be claiming to typically waste through dissipation into the environment and solar energy used for generating or recovering the energy to power up the notebook (Mohd 
Izam and Jahariah, 2013). The self-powered notebook or laptop using recovered waste heat and solar are designed to be a portable system.

From the proposed architecture, the boost converter should be able to deliver a consistent output voltage between $20 \mathrm{~V}$ to $24 \mathrm{~V}$ from $5 \mathrm{~V}$ input source. When the voltage is boosted to the desired input, the energy storage will be operated and the harvested energy is reserved in a storage capacitor. The last part before connecting to the laptop or notebook, a voltage regulator will be activated to set the amount of the output voltage from $12 \mathrm{~V}$ to $20 \mathrm{~V}$.

\section{Materials and Methods}

The proposed design flow chart for this research work is as shown in Fig. 4. Firstly, it is important to begin with comprehensive literature reviews to investigate the existing architecture of LPHEH. In order to perform this research work, the research survey from the literature on the LPHEH designs and charging techniques need to be explored. Then, the new architecture of LPHEH will be developed and designed by stages, modeled and simulated using PSPICE software. Then, the developed LPHEH will be simulated, synthesis using Mentor Graphics and coding using Verilog architecture and to be completed with the implementation of the LPHEH for laptops and notebooks.In this level, Mentor Graphics will be used to analyze and redesigned if there is any error in simulation. Then, this proposed LPHEH architecture will be downloaded into Field Programmable Gate Array (FPGA) boards for functional verification.

The verified Low Power Hybrid Energy Harvester circuits will be developed using $0.13 \mu \mathrm{m}$ CMOS technology. Then, the developed LPHEH will be generated in GSDII format and finally, the layout of LPHEH will be tested and analyzed using CALIBRE tools from Mentor Graphics.

\section{Conclusion}

The investigation and design of LPHEH have been proposed with the hybrid sources from TEG (thermal) and solar. This proposed LPHEH will be developed and designed, modeled and simulated using PSPICE software and the charging process will be performed using Verilog from Mentor Graphics. The main target and goal of this research are to reduce the power losses and to increase the energy conversion efficiency. This research also aimed to contribute to the reusable alternative energy from the waste heat to power up the notebook and eliminates the need for an external power source (Yao et al., 2009). This research work will be continued by designing a high performance DC-DC Power Converter (Boost Converter). The boost converter is designed so that it is capable of increasing the output voltage and to achieve maximum power as required by the laptop and notebook (Richelli et al., 2009).

The expected final result is to gain an approximation of more than $90 \%$ efficiency with input voltage range between $5 \mathrm{~V}$ to $12 \mathrm{~V}$ and output regulated voltage range between $12 \mathrm{~V}$ to $20 \mathrm{~V}$. The testing and verification results will show that the notebook can be powered up and operated in double or triple of hours as compared to a normal operating notebook.

\section{Acknowledgement}

The authors gratefully acknowledge the financial support by Universiti Kebangsaan Malaysia (UKM) internal grant GUP-2015-21 and to theMinistry of Education Malaysia research grant (FRGS/2/2014/TK03/UKM/02/).

\section{Author's Contributions}

Hanani Mohamed Nadzirin: Investigation on the current research and existing architecture of LPHEH for laptop and notebook from literature review, summarizing and analyzing information and data, collecting all data and preparing the document.

Jahariah Sampe: Supervised and organized the plan and research study, assisting the proposed research procedure and method, giving comments, reviewing and greatly improved the document.

Muhammad Shabiul Islam: Assisting with guidance and reviewing the document.

Noorfazila Kamal: Assisting with guidance and sharing knowledge on the research study.

\section{Ethics}

This article is original and has not published elsewhere.

\section{References}

Abdelmoaty, A.A. and A. Fayed, 2015. A single-step, single-inductor energy-harvesting based power supply platform with a regulated battery charger for mobile applications. Proceedings of the IEEE Applied Power Electronics Conference and Exposition, 15-19 March, IEEE Xplore Press, pp: 666-669. DOI: 10.1109/APEC.2015.7104421

Abdul Rahman, Z.H., M.H. Md Khir, Z.A. Burhanuddin, K. Ashraf and A.A. Abd et al., 2013. CMOS based thermal energy generator for low power devices. Int. J. Scientific Engineering Res., 4: 159-164.

Alhawari, M., B. Mohammad, H. Saleh and M. Ismail, 2013. A survey of thermal energy harvesting techniques and interface circuitry. Proceedings of the Through ACES Advanced Technology Investment Company (ATIC), Abu Dhabi, UAE, pp: 381-384. DOI: 10.1109/ICECS.2013.6815434 
Basel, I.I. and W.H. Ahmed, 2009. Thermoelectric power generation using waste-heat energy as an alternative green technology. Department of Mechanical Engineering, Lakehead University, Canada

Beker, L., O. Zorlu, H. Kulah and A. Muhtaroglu, 2011. Hybrid energy harvesting from keyboard. Proceedings of the International Conference on Energy Aware Computing (ICEAC), IEEE Conference Publications, pp: 1-4. DOI: 10.1109/ICEAC.2011.6136691

Calhoun, B.H., S. Khanna, Y. Zhang, J. Ryan and B. Otis, 2010. System design principles combining sub-threshold circuit and architectures with energy scavenging mechanisms. Proceedings of the IEEE International Symposium on Circuits and Systems (ISCAS), 30 May-2 June, IEEE Xplore Press, pp: 269-272. DOI: 10.1109/ISCAS.2010.5537887.

Carlson, E.J., K. Strunz and B.P. Otis, 2009. A $20 \mathrm{mV}$ input boost converter for thermoelectric energy harvesting. Proceedings of the Symposium on VLSI Circuits Digest of Technical Papers, pp: 162-163.

Carlson, E.J., K. Strunz and B.P. Otis, 2010. A $20 \mathrm{mV}$ input boost converter with efficient digital control for thermoelectric energy harvesting. IEEE J. SolidState Circuits, 45: 741-750. DOI: $10.1109 /$ JSSC.2010.2042251

Carreon-Baustista, S., A. Eladawy, A.N. Moheildin and E. Sanchez-Sinencio, 2014. Boost converter with dynamic input impedance matching for energy harvesting with multi-array thermoelectric generators. IEEE J. Solid-State Circuits, 61: 5345-5353. DOI: 10.1109/TIE.2014.2300035.

Chandrakasan, A.P., D.C. Daly, J. Kwong and Y.K. Ramadass, 2008. Next generation micro-power systems. Proceedings of the IEEE Symposium on VLSI Circuits, Honolulu, HI, pp: 2-5. DOI: 10.1109/VLSIC.2008.4585930

Colomer-Farrarons, J., P. Miribel-Catala, A. Saiz-Vela and J. Samitier, 2011. A multiharvested selfpowered system in a low-voltage low-power technology. IEEE Trans. Industrial Electronics, 58: 4250-4263. DOI: 10.1109/TIE.2010.2095395

Dayal, R., K. Modepalli and L. Parsa, 2013. A new optimum power control scheme for low-power energy harvesting systems. IEEE Trans. Industry Applications, 49: 2651-2661. DOI: 10.1109 /TIA.2013.2264043

Dhople, S., J. Ehlmann, A. Davoudi and P. Chapman, 2010. Multiple-input boost converter to minimize power losses due to partial shading in photovoltaic modules. Proceedings of the IEEE Energy Conversion Congress and Exposition, Sep. 12-16, pp: 2633-2636.

DOI: 10.1109/ECCE.2010.5618013.
Doms, I., P. Marken, C.V. Hoof and R.P. Mertens, 2009. Integrated capacitive power management circuit for thermal harvesters with output power 10 to $1000 \mu \mathrm{W}$. Proceedings of the IEEE International Solid State Circuit Conference, pp: 299-301. DOI: 10.1109/ISSCC.2009.497742

Farah Fatin, Z., S. Jahariah, M.S. Islam and M.A. Mohamed, 2015a. Architecture of ultra low power micro energy harvester using rf signal for health care monitoring system: A Review. Am. J. Applied Sci., $\quad$ 12: 335-344. DOI: 10.3844/ajassp.2015.335.344

Farah Fatin, Z., S. Jahariah, M.S. Islam, M.A. Mohamed and S.A. Wahab, 2015b. Optimization of RF-DC converter in micro energy harvester using voltage boosting network and bulk modulation technique for biomedical devices. K. Terengganu, Malaysia.

Hamilton, M.C., 2012. Recent advances in energy harvesting technology and techniques. Proceedings of the 38th Annual Conference on IEEE Industrial Electronics Society, pp: 6297-6304. DOI: $10.1109 /$ IECON.2012.6389019

Han, H.S., Y.H. Kim, S.Y. Kim, S. Um and J.M. Hyun, 2010. Performance measurement and analysis of a thermoelectric power generator. Proceedings of the 12th IEEE Intersociety Conference on Thermal and Thermo Mechanical Phenomena in Electronic Systems (ITherm), pp: 1-7. DOI: 10.1109/ITHERM.2010.5501389

Inge, D., P. Marken, C.V. Hoof and R.P. Mertens, 2009. Capacitive power management circuits for micropower thermoelectric generators with a $1.4 \mu \mathrm{A}$ controller. IEEE J. Solid-State Circuits, 44: 28242833. DOI: $10.1109 /$ JSSC.2009.2027546

Kadivel, K., Y. Ramadass, U. Lyles, J. Carpenter and V. Ivanov et al., 2012. A 330nA energy harvesting charger with battery management for solar and thermoelectric energy harvesting. Proceedings of the IEEE International Solid-State Circuits Conference Digest of Technical Papers (ISSCC), pp: 106-108. DOI: $10.1109 /$ ISSCC.2012.6176896

Kalyanaraman, K. and J. Babu, 2010. Power harvesting system in mobile phones and laptops using piezoelectric charge generation. Proceedings of the World Congress on Engineering and Computer Science (WCECS 10), Oct. 20-22, San Francisco, USA.

Michelle, L.S.M., S.H.M. Ali, S. Jahariah and M.S. Islam, 2014. Modelling of hybrid energy harvester with DC-DC boost converter using arbitary input sources for ultra-low-power Micro-devices. Proceedings of the 11th IEEE International Conference on Semiconductor Electronics (ICSE'14), pp: 28-31. DOI: 10.1109/SMELEC.2014.6920787 
Mohd Izam, A.J. and S. Jahariah, 2013. Experimental investigation of thermoelectric generator modules with different techniques of cooling system. Am. J. Eng. Applied Sci., 6: 1-7. DOI:10.3844/ajeassp.2013.1.7

Motiur, D.M., M.S. Islam, Jahariah S. and Sawal Hamid Md. Ali, 2015. An Architecture of ULP energy harvesting power conditioning circuit using piezoelectric transducer for wireless sensor network: A review. Asian J. Scientific Res. DOI: 10.3923/ajsr.2015.

Musa, A.A., S. Jahariah, I. Md Shabiul and B.Y. Majlis, 2016. Ultra low power energy harvester using hybrid input for wireless communication devices-a review. J. Theoretical Applied Inform. Technology. DOI: 10.1109/RSM.2015.7354974.

Porcarelli, D., D. Brunelli, M. Magno and L. Benini, 2012. A Multi-Harvester architecture with hybrid storage devices and smart capabilities for low power systems. Proceedings of the International Symposium on Power Electronics, Electrical Drives, Automation and Motion (SPEEDAM), Sorrento. pp: 946-951. DOI: 10.1109/SPEEDAM.2012.6264533

Richelli, A., L. Colalongo, S. Tonoli and Z.M. KovacsVajna, 2009. A 0.2-1.2 DC/DC boost converter for power harvesting applications. Trans. Power Electronics, 24: 1541-1546. DOI: 10.1109/TPEL.2009.2013224.

Sarker, M.R, S.H.M. Ali, M. Othman and S. Islam, 2013. Designing a batteryless piezoelectric based energy harvesting interface circuit with $300 \mathrm{mV}$ startup voltage. J. Physics: Conference Series, 431: 1-8. DOI: $10.1088 / 1742-6596 / 431 / 1 / 012025$

Saurav, B. and P.C. Anantha, 2012. Platform architecture for solar, thermal and vibration energy combining with MPPT and single inductor. IEEE J. Solid-State Circuits, 47: 2199-2215. DOI: 10.1109/JSSC.2012.2197239

Semsudin, N.A.A., J. Sampe, M.S. Islam and A.R. Md Zain, 2015a. Architecture of ultra-low-power micro energy harvester using hybrid input for biomedical devices. Asian J. Scientific Res., 8: 212-224. DOI: 10.3923/ajsr.2015.212.224

Semsudin, N.A.A., J. Sampe, M.S. Islam, A.R.M. Zain and D.D. Berhanuddin, 2015b. Designing a boost converter of micro energy harvester using thermal and vibration input for biomedical devices. Proceedings of the IEEE Regional Symposium on Micro and Nanoelectronics (RSM), Kuala Terengganu, pp: 1-4.
Shi, C., B. Miller, K. Mayaram and T. Fiez, 2011. A multiple-input boost converter for low-power energy harvesting. IEEE Trans. Circuits Systems II; Express Briefs, 58: 827-831. DOI: 10.1109/TCSII.2011.2173974

Stark, B.H., G.D. Szarka and E.D. Rooke, 2010. Start-up circuit with low minimum operating power for microwatt energy harvesters. IET Circuits, Devices Systems, 5: 267-274. DOI: $10.1049 /$ iet-cds.2010.0199

Torres, E.O., L.A. Milner and G.A. Rincon-Mora, 2008. Hybrid supplies for wireless micro-systems, the Electrochemical Society: Interface, pp: 57-60.

Weng, P.S., H.Y. Tang, P.C. Ku and L.H. Lu, 2013. 50 $\mathrm{mV}$-Input batteryless boost converter for thermal energy harvesting. IEEE J. Solid-State Circuits, 48: 1031-1041. DOI: 10.1109/JSSC.2013.2237998

Xu, C., C. Pan, Y. Liu and Z.L. Yang, 2012. Hybrid cells for simultaneously harvesting multi-type energies for self-powered micro/nanosystems. Nano Energy, 1: 259-272. DOI: $10.1016 /$ j.nanoen.2012.01.002

Yen, K.T. and K.P. Sanjib, 2011. Energy harvesting from hybrid indoor ambient light and thermal energy sources for enhanced performance of wireless sensor network. IEEE Trans. Industrial Electronics, 58: 4424-4434. DOI: 10.1109/TIE.2010.2102321

Yildiz, F., S. Houston and K.L. Coogler, 2014. Thermoelectric Generator through an air conditioning condenser. Proceedings of the 121st ASEE Annual Conference and Exposition, Jun. 5-18, Indianapolis.

Yao, D.J., K.J. Yeh, C.T. Hsu, B.M. Yu and J.S. Lee, 2009. Efficient Reuse of Waste Energy. IEEE Trans. Nanotechnology Magazine, 3: 28-33. DOI: $10.1109 /$ MNANO.2009.932420.

Yogesh, K.R. and A.P. Chandrakasan, 2011. A batteryless thermoelectric energy harvesting interface circuit with $35 \mathrm{mV}$ startup voltage. IEEE J. SolidState Circuits, 46: 333-341. DOI: $10.1109 /$ JSSC.2010.2074090. 